\title{
EVOLUÇÃO DA EXPERIÊNCIA NO VAREJO DE SERVIÇOS: UM EXEMPLO DO SETOR DE TELECOMUNICAÇÕES BRASILEIRO
}

EVOLUTION OF EXPERIENCE IN RETAIL SERVICES: AN EXAMPLE OF BRAZILIAN TELECOMMUNICATIONS SECTOR

\section{Bruno Antunes Oliveira}

Mestrando em Administração pela Faculdade de Economia, Administração e Contabilidade da Universidade de São Paulo - FEA USP

E-mail: brunoaol@uol.com.br (Brasil)

\section{Ana Carolina Toledo}

Mestranda em Administração pela Universidade Nove de Julho - UNINOVE

E-mail: ana.caro.toledo@uol.com.br (Brasil)

\section{Evandro Luiz Lopes}

Doutor em Administração pela Universidade Nove de Julho - UNINOVE Professor da Universidade Nove de Julho - UNINOVE

E-mail: elldijo@uninove.br (Brasil) 


\title{
EVOLUÇÃO DA EXPERIÊNCIA NO VAREJO DE SERVIÇOS: UM EXEMPLO DO SETOR DE TELECOMUNICAÇÕES BRASILEIRO
}

\section{RESUMO}

O propósito desta pesquisa é, por meio de um estudo de caso gerado a partir de um estudo de caso, exemplificar a evolução do varejo de serviços. Como já se sabe, o setor de serviços está em franco crescimento tanto no contexto mundial quanto no Brasil. Diante da competição instalada, os varejistas de serviços estão adotando várias inovações, para tornar o ambiente de decisão de compra cada dia mais atrativo. Neste estudo, por meio da revisão bibliográfica da teoria sobre varejo e visita em campo a uma nova "loja conceito" da Vivo S/A (empresa multinacional de telecomunicações), os autores confrontam as estratégias comerciais varejistas adotadas pela empresa com as principais características distintas do setor de serviços. Os principais achados indicam que o Marketing Experiencial ainda está em processo de maturação no contexto brasileiro.

Palavras-chave: Varejo; Serviços; Marketing de experiência.

\section{EVOLUTION OF EXPERIENCE IN RETAIL SERVICES: AN EXAMPLE OF BRAZILIAN TELECOMMUNICATIONS SECTOR}

\begin{abstract}
The purpose of this research is to exemplify the development of retail services, using a case study. The service sector is booming both globally and in Brazil. Faced with competition, retailers are adopting several innovative services to make buying decisions more attractive. In this study, through a literature review of the theory of retail and through a field visit to a new "concept store" from Vivo S/A (a multinational telecommunications company), the authors explore the marketing strategies adopted by the company, especially those in the service sector. The main findings indicate that Experiential Marketing is still in the process of maturation in the national context.
\end{abstract}

Key words: retail; services; Experiential Marketing

Revista Brasileira de Marketing - REMark, São Paulo, v. 12, n. 1, p. 223-250, jan./mar. 2013. 


\section{INTRODUÇÃO}

O varejo vem assumindo uma importância crescente no panorama empresarial brasileiro e mundial. Segundo Parente (2010), à medida que as empresas varejistas se expandem, passam a adotar avançadas tecnologias de informação e gestão, e desempenham papel cada vez mais importante na modernização do sistema de distribuição e da economia brasileira.

Ao longo das últimas décadas, as instituições varejistas vêm atravessando um intenso ritmo de transformação. Ao longo desses 40 anos, muitos modelos de lojas foram cedendo lugar aos novos formatos, mais eficientes e mais adequados às novas necessidades do mercado consumidor (Parente, 2010, p.15).

Na integração de esforços de Marketing e de comunicação, é preponderante estar sempre um passo à frente dos competidores, visando a um trabalho de longo alcance, analisando e agindo, considerando todas as possibilidades do mercado (Blessa, 2005). Narver e Slater (1990) definem orientação para o mercado como uma cultura organizacional que, de forma mais efetiva e eficiente, cria os comportamentos necessários para a geração de valor superior para os clientes e assim, desempenho superior para o negócio. Para as empresas, entre os diversos benefícios de possuir uma carteira de clientes altamente satisfeitos, incluem-se a menor elasticidade dos preços, o afastamento de seus consumidores das ofertas da concorrência, a redução dos custos de transações futuras, custos de falha reduzidos, um menor custo para atrair novos clientes e a melhora da reputação da empresa (Fornell, 1992).

Esta filosofia que valoriza o papel do cliente e coloca a sua satisfação como essencial para o alcance de desempenho superior, adquire maior relevância no setor de serviços. Empresas, instituições e indivíduos estão cada vez mais desejosos de trocar dinheiro por tempo e de comprar serviços em vez de gastar tempo fazendo coisas por si mesmas (Hoffman et al., 2009).

Setores emergentes de serviços ganham representatividade em muitas economias que antes eram conhecidas pelo seu poder industrial, além de captar e dominar grande parte da força de trabalho. Neste setor, o imperativo de serviço reflete a visão de que os aspectos intangíveis dos produtos estão se tornando características fundamentais que os diferenciam no mercado.

O entendimento do varejo enquanto modalidade de serviços é o objetivo de estudo deste trabalho, considerando o surgimento de novas indústrias no setor de serviços e do "imperativo de serviços", que segundo Hoffman et al. (2009), reflete a visão de que os aspectos intangíveis dos produtos estão se tornando características fundamentais que os diferenciam no mercado. Neste contexto, o Marketing experiencial, tema recente na literatura, contribui com possíveis formas de desenvolvimento dos aspectos intangíveis da prestação de serviço no varejo.

Revista Brasileira de Marketing - REMark, São Paulo, v. 12, n. 1, p. 223-250, jan./mar. 2013. 
Contrapondo-se ao conceito racional e utilitarista do modelo do comportamento de compras do consumidor, proposto por Kotler e Keller (2006), o Marketing de experiências explora os cinco sentidos humanos para que os clientes possam ter uma relação de proximidade com os produtos ofertados pelas empresas, criando associações permanentes. Além disso, ele está relacionado ao simbolismo e sentimentos que uma marca evoca para os seus clientes. Todavia, este conceito ainda é pouco explorado, seja em artigos acadêmicos ou no mundo corporativo.

A "Era da Economia da Experiência", descrito por autores como Han e Sun (2011), Ma (2009), ao contrário da visão econômica tradicional - centrada nos produtos e nas vantagens de preços reduzidos - deve ser baseada mais na situação cotidiana das pessoas, realçando as experiências sensoriais dos consumidores e conseguindo despertar a atenção dos mesmos para a identidade de marca das ofertas das empresas. A economia da experiência é uma forma das empresas associarem serviços às suas ofertas, criando sentimentos de valor para seus consumidores durante o consumo.

Ao usarem o Marketing de experiência, as empresas podem criar diferenciação para seus produtos, estimular seus clientes a comprarem mais e adicionar valor aos bens ou serviços que comercializa. Compactuando com este ponto de vista, Dagger e O'brien (2010) argumentam que os relacionamentos entre clientes e empresa mudam para melhor quando o nível de experiência daqueles aumenta, culminando com aumento no nível de lealdade para com a empresa.

Em levantamento sobre estudos brasileiros realizados no âmbito do Marketing de serviços, Da Rocha e Ferreira da Silva (2006) concluíram que a maioria dos estudos está fortemente concentrada em investigar o comportamento pós-compra de serviços, seguindo a linha mestra dos estudos internacionais. Mais ainda, a maior parte dos estudos se concentrou em dois construtos: qualidade e satisfação. Os autores indicam ainda que explorações teóricas e empíricas em torno do tema de cenários de serviços são escassas e concentradas e que o estudo do processo de escolha do consumidor de serviços também se limitou a poucos estudos e centros de investigação.

O objetivo do estudo é aprofundar o conhecimento de um conceito relativamente recente na literatura, referente ao Marketing experiencial. O escopo de estudo se situa no âmbito da prática de varejo e serviços. Assim, busca-se entender de que forma o desempenho de ações relacionadas ao Marketing experiencial podem contribuir para a superação de questões inerentes à natureza da prestação de serviços, que têm características distintivas amplamente debatidas na literatura do Marketing de varejo e de serviços.

Busca-se, portanto, por meio de uma revisão teórica nos temas de varejo e serviços e da aplicação prática de uma pesquisa de campo no mercado de telecomunicações, que utilizou a 
netnografia, investigar e analisar a conceituação de varejo de serviços, bem como, avaliar uma proposta específica de diferenciação varejista com foco na evolução do uso da evidência física (loja) como ambiente de experiência e relacionamento de marca. Para tanto, este estudo está estruturado em quatro seções, além desta breve introdução. A segunda seção é constituída pela revisão bibliográfica realizada. A terceira seção descreve o método utilizado no estudo. A seção seguinte descreve o caso estudado e, a última seção, comenta os principais achados do estudo.

\section{REVISÃO TEÓRICA}

O principal objetivo desta seção é descrever os principais pilares teóricos utilizados nesta pesquisa.

\subsection{VAREJO}

Na definição de Juracy Parente (2010), varejo consiste em todas as atividades que englobam o processo de venda de produtos e serviços para atender a uma necessidade pessoal do consumidor final. De forma bastante semelhante, Kotler e Keller (2006) afirmam que o varejo inclui todas as atividades relativas à venda de produtos ou serviços diretamente ao consumidor final, para uso pessoal e não comercial.

O varejista, para Parente (2010), é qualquer instituição cuja atividade principal consiste no varejo, isto é, na venda de produtos e serviços para o consumidor final. Para Kotler e Keller (2006), um varejista ou uma loja de varejo é qualquer empreendimento comercial cujo faturamento provenha principalmente da venda de pequenos lotes no varejo. Afirmam ainda que qualquer organização que venda para os consumidores finais - seja um fabricante, atacadista ou varejista está fazendo varejo. Não importa como os produtos ou serviços são vendidos (pessoalmente, pelo correio, por telefone, por máquina de vendas ou pela Internet) ou onde eles são vendidos (em uma loja, na rua, na casa do consumidor).

\subsection{NÍVEIS E FLUXOS DO CANAL DE DISTRIBUIÇÃO}

Parente (2010) apresenta o conceito de estrutura e níveis do canal existentes entre o fabricante e o consumidor, com diferentes níveis de intermediários: em uma estrutura de nível dois, o fabricante vende diretamente ao consumidor; em uma estrutura de nível três, o varejista se coloca

Revista Brasileira de Marketing - REMark, São Paulo, v. 12, n. 1, p. 223-250, jan./mar. 2013. 
entre o fabricante e o consumidor; em uma estrutura de nível quatro, um atacadista e um varejista se colocam entre o fabricante e o consumidor; e, finalmente, em uma estrutura de nível cinco, além de atacadista e varejista, também um agente se antepõe ao atacadista, no fluxo entre o fabricante e o consumidor.

As ações que decorrem neste curso de mercadorias e informações no canal entre o fabricante e o consumidor envolvem cinco fluxos, segundo Parente (2010): um fluxo físico, de transporte; um fluxo de propriedade, de posse do produto; um fluxo de informação; um fluxo de pagamento; e um fluxo de promoção, que envolve propaganda, publicidade e promoção de vendas.

$\mathrm{Na}$ composição do varejo, Parente (2010) defende a teoria dos 6 Ps, onde duas novas variáveis são apresentadas: o P de Pessoal (atendimento e serviços) e o P de apresentação (presentation). A junção do mix de Marketing a essas duas variáveis é capaz de oferecer uma experiência de marca, se bem trabalhada e pautada nos conceitos do Marketing experiencial.

\subsection{MARKETING DE SERVIÇOS}

O setor de serviços tem apresentado um aumento de participação considerável na economia global. Segundo Lovelock e Wright (2001), os serviços constituem o grosso da economia de hoje, não só no Brasil, onde respondem por 55\% do Produto Interno Bruto (PIB), mas também no mundo - nos EUA e no Canadá respondem por $72 \%$ e $67 \%$ do PIB, respectivamente. Las Casas (2000) destaca o maior poder aquisitivo da população, que permite que as tarefas tidas como mais rotineiras sejam transferidas a terceiros e prestadores de serviços. Grönroos (1995) defende ainda que à medida que a sociedade se transforma, as pessoas se tornam mais ricas e uma atitude diferente com relação à vida se desenvolve. As pessoas, então, passam a gastar mais em serviços.

Como apontam Da Rocha e Ferreira da Silva (2006), o interesse pelo Marketing de serviços, particularmente, nos últimos 20 anos, encontra-se ligado à importância econômica dos serviços nas economias pós-industriais. Mais ainda, à medida que se reduzem as possibilidades de diferenciação de produtos, devido ao amadurecimento dos mercados, as empresas são levadas a desenvolver vantagens competitivas centradas na oferta ampliada de serviços.

As primeiras publicações sobre o tema discutiam a natureza dos serviços, suas características e a aplicabilidade dos conceitos tradicionais de Marketing ao Marketing de serviços. Entre os pioneiros no desenvolvimento teórico cabe destacar os trabalhos de Grönroos e Lovelock dos quais derivam conceitos iniciais de qualidade percebida dos serviços, além dos trabalhos de Parasuraman, Zeithaml e Berry com foco na teoria dos gaps de qualidade, com a proposição da escala Servqual de qualidade percebida em serviços.

Revista Brasileira de Marketing - REMark, São Paulo, v. 12, n. 1, p. 223-250, jan./mar. 2013. 
Pode-se dizer que vivemos uma nova era de serviços globais. Dentre os aspectos citados por Hoffman et al. (2009) como fatores críticos dessa nova realidade, vale ressaltar o maior envolvimento dos clientes nas decisões estratégicas de negócio, o aumento da autonomia dos funcionários para desenvolver soluções personalizadas nas solicitações de clientes e, principalmente, o "imperativo de serviço", em que os aspectos intangíveis do produto estão se tornando cada vez mais características fundamentais que os diferenciam no mercado.

Os efeitos dessa nova realidade são majoritariamente positivos e muitos autores consideram que o aumento do setor de serviços tem sido o responsável pelo aumento da riqueza e do nível de emprego na sociedade. (Grönroos, 1995; Lovelock e Wright, 2001; Hoffman et al., 2009; Zeithaml e Bitner, 2003).

\subsubsection{CARACTERÍSTICAS DISTINTIVAS DE SERVIÇOS}

Os serviços são a proposta de valor de uma organização a uma pessoa ou a um grupo de pessoas com o objetivo de satisfação de suas necessidades. Para Lovelock e Wright (2001) serviço é um ato ou desempenho oferecido por uma parte à outra.

Embora o processo possa estar ligado a um produto físico, o desempenho é essencialmente intangível e normalmente não resulta em propriedade de nenhum dos fatores de produção. Corroboram com esta visão Zeithaml e Bitner (2003), quando afirmam que fica claro que os serviços não são produzidos apenas por empresas de serviços, mas também fazem parte daquilo que os fabricantes de produtos manufaturados oferecem. Ainda neste sentido, Grönroos (1995) defende que a maioria das empresas de fabricação no chamado setor industrial da economia tem que oferecer a seus clientes uma variedade de serviços como parte integral de suas ofertas.

Pode-se dizer que a distinção entre o que é um bem ou produto do que é um serviço ou um serviço complementar não é algo claro. Hoffman et al. (2009) acreditam que na verdade é difícil, se não impossível, fornecer um exemplo de um bem puro ou de um serviço puro. Quando comparados aos bens físicos, quatro características básicas podem ser identificadas nos serviços, de acordo com Grönroos (1995): (1) serviços são mais ou menos intangíveis; (2) serviços são atividades ou uma série de atividades em vez de coisas; (3) serviços são, pelo menos até certo ponto, produzidos e consumidos simultaneamente; (4) o cliente participa do processo de produção, pelo menos até certo ponto. Parasuraman et al. (1985), após extensa revisão do tema com base em diversos autores, listaram as quatro características que diferenciam serviços de produtos, ou bens de consumo: intangibilidade, inseparabilidade, heterogeneidade e perecibilidade.

Conforme revisão realizada por Zolfagharian (2007), a literatura sugere diversas diferenças entre serviços e produtos. Duas dessas diferenças, nomeadamente intangibilidade e inseparabilidade 
da produção-consumo, são fundamentais e todas as outras características, incluindo perecibilidade e heterogeneidade (Zeithaml, Parasuraman E Berry, 1985) são derivadas dessas duas (Bateson, 1985; Eiglier, 1977; Hill, 1977).

Intangibilidade significa que falta, aos serviços, a substância física. Pelo fato de serviços serem atuações e ações mais do que propriamente objetos, eles não ser vistos, sentidos, ouvidos, cheirados ou tocados da mesma forma que podemos sentir os bens tangíveis Assim, além de não poderem ser armazenados, não podem ser patenteados legalmente e novos conceitos de serviços podem ser facilmente copiados pela concorrência. Além disso, torna-se difícil determinar os custos reais da "unidade de serviço" e a relação preço / qualidade é complexa (Zeithaml E Bitner, 2003, p.36). Lovelock e Wright (2001) acrescentam ainda que a noção de serviço, como realização que não pode ser tocada ou embrulhada e carregada, leva a uma metáfora teatral para a administração de serviços.

Portanto, as estratégias desenvolvidas para contrabalançar os desafios propostos pela intangibilidade incluem o uso de indícios tangíveis como evidência física concreta, desenvolvimento da imagem organizacional e de fontes pessoais de informação que os clientes acessam quando escolhem provedores de serviços (Hoffman et al., 2009; Grönroos, 1995).

Inseparabilidade diz respeito à relação intrínseca entre provedores de serviços e seus clientes. De modo geral, os serviços são produzidos e consumidos simultaneamente. Diferentemente dos produtores de bens, os provedores de serviços estabelecem interações cara a cara com seus clientes, que estão diretamente envolvidos no processo de produção do serviço (HOFFMAN et al., 2009). Zeithaml e Bitner (2003, p.37) acrescentam ainda que "enquanto a maior parte dos bens é produzida antecipadamente para então ser vendida e consumida, a maior parte dos serviços é primeiro vendida, e então, produzida e consumida simultaneamente.”. Para Grönroos (1995) é a parte visível das atividades de produção que conta na mente do cliente. Assim, o controle da qualidade e o Marketing têm que ter lugar, portanto, no momento e no lugar da produção e consumo do serviço simultaneamente.

Por fim, Lovelock e Wright (2001) destacam ainda que os clientes sejam ativamente envolvidos em ajudar a criar o produto do serviço, pelo autoatendimento ou pela cooperação com o pessoal de serviços. Dessa forma, as empresas de serviços têm muito a ganhar por tentarem educar seus clientes para torná-los mais competentes. Entre as possíveis soluções para os problemas de inseparabilidade, Hoffman et al. (2009) sugerem o maior cuidado com a seleção e treinamento do pessoal de contato com o público, o gerenciamento do cliente e o uso de múltiplas localizações.

Heterogeneidade relaciona-se à variabilidade inerente ao processo de prestação de serviços, 
pois dependem de por quem, onde e quando são fornecidos. Segundo Zeithaml e Bitner (2003), a heterogeneidade ocorre pelo fato de dois clientes nunca serem exatamente os mesmos; cada qual terá demandas exclusivas ou suas experiências do serviço ocorrerão de forma muito particular. Em decorrência disso, erros e falhas são mais frequentes e mais difíceis de ocultar (Lovelock; Wright, 2001).

O principal problema de Marketing ligado à heterogeneidade é que a padronização e o controle de qualidade são difíceis de serem mantidos regularmente pela empresa de serviços. O potencial de heterogeneidade pode ser ampliado ainda mais quando os serviços são executados por um terceiro. (Grönroos, 1995; Zeithaml; Bitner, 2003). Possíveis estratégias consideram a padronização do processo por máquinas ou alternativamente, a prestação de serviços customizados que satisfazem necessidades individuais do cliente. Essa definição dependerá de uma hierarquia de critérios do cliente tais como preço, velocidade de entrega e consistência de desempenho.

Para Zeithaml e Bitner (2003), a perecibilidade refere-se ao fato de os serviços não poderem ser preservados, estocados, revendidos ou devolvidos. Segundo Hoffman et al. (2009), no entanto, a perecibilidade não se configura como um problema quando a demanda é estável. O desafio surge quando não há equilíbrio entre a demanda e a oferta de serviços, pois os serviços que não são usados na hora em que foram programados cessam de existir. Grönroos (1995) defende que o planejamento da capacidade se torna uma questão crítica e que embora os serviços não possam ser mantidos em estoque, pode-se tentar manter os clientes em estoque. Porém, como apontam Lovelock e Wright (2001), existem limites de tempo em que os clientes estarão dispostos a ficar esperando, pois os clientes de hoje são cada vez mais sensíveis ao tempo, e a velocidade muitas vezes é um elemento fundamental para o bom serviço.

Por fim, Hoffman et al. (2009), propõem, como possíveis soluções à questão da perecibilidade, formas de (1) controle estratégico da demanda: por meio da fixação criativa de preços, do uso de um sistema de reservas, do desenvolvimento de serviços complementares ou do desenvolvimento de demanda fora do período de pico; e (2) controle estratégico da oferta: por meio da utilização de funcionários de meio período, de compartilhamento da capacidade com outros prestadores de serviços, de uso de terceiros ou inclusive contando com aumento da participação do cliente no processo.

Assim, à luz destas quatro características distintivas, Kotler e Keller (2006) defendem que os profissionais de Marketing precisam ser capazes de transformar serviços intangíveis em benefícios concretos. As empresas devem desenvolver, primeiro, uma imagem de como querem que seja a percepção do cliente quanto a determinada experiência. Depois, devem planejar um conjunto consistente de sinais de contexto e desempenho para sustentar essa experiência.

Revista Brasileira de Marketing - REMark, São Paulo, v. 12, n. 1, p. 223-250, jan./mar. 2013. 


\subsubsection{EXPERIÊNCIA EM SERVIÇOS}

Hoffman et al. (2009) defendem que, embora o processo de decisão do cliente se aplique tanto a bens quanto a serviços, existem considerações exclusivas a respeito dos serviços. Cabe verificar que o consumo é mais complexo para serviços, pois a produção, a aquisição e o uso dos serviços tornam-se mais complicados em um único processo.

Lovelock e Wright (2001) colocam o "encontro de serviços" como o período de tempo durante o qual os clientes interagem diretamente com um serviço. A experiência de serviço como um todo pode ser reduzida a um único encontro ou abrange uma sucessão de encontro que pode distribuir-se por um determinado período de tempo, envolver vários funcionários e até acontecer em locais diferentes. Para esta mesma ideia, Grönroos (1995) estabeleceu o conceito de "hora da verdade" como as interações entre os clientes e os representantes da empresa ou as várias áreas / setores da empresa. A sobreposição de etapas existente em serviços traz implicações para o Marketing:

(...) por causa do extenso processo de prestação do serviço, muitos acreditam que a avaliação pós-compra do cliente ocorre tanto durante quanto depois da utilização dos serviços, e não apenas depois dela. Do ponto de vista do Marketing, isso oferece a oportunidade de influenciar diretamente a avaliação do cliente durante o processo de prestação do serviço. (Hoffman et al., 2009, p.116)

Para ilustrar a importância da experiência do cliente com os diversos elementos do serviço prestado, Langeard et al. (1981) desenvolveram o modelo Servuction. Combinando as palavras "service" e "production" o conceito sustenta que o cliente coproduz o serviço que consome e sua percepção sobre o serviço é influenciada por dois tipos de elementos: o que é visível ao cliente (ambiente inanimado, provedores de contato pessoal e outros clientes) e o que não é (a organização e os sistemas invisíveis).

Revista Brasileira de Marketing - REMark, São Paulo, v. 12, n. 1, p. 223-250, jan./mar. 2013. 
Figura 1: Modelo Servuction

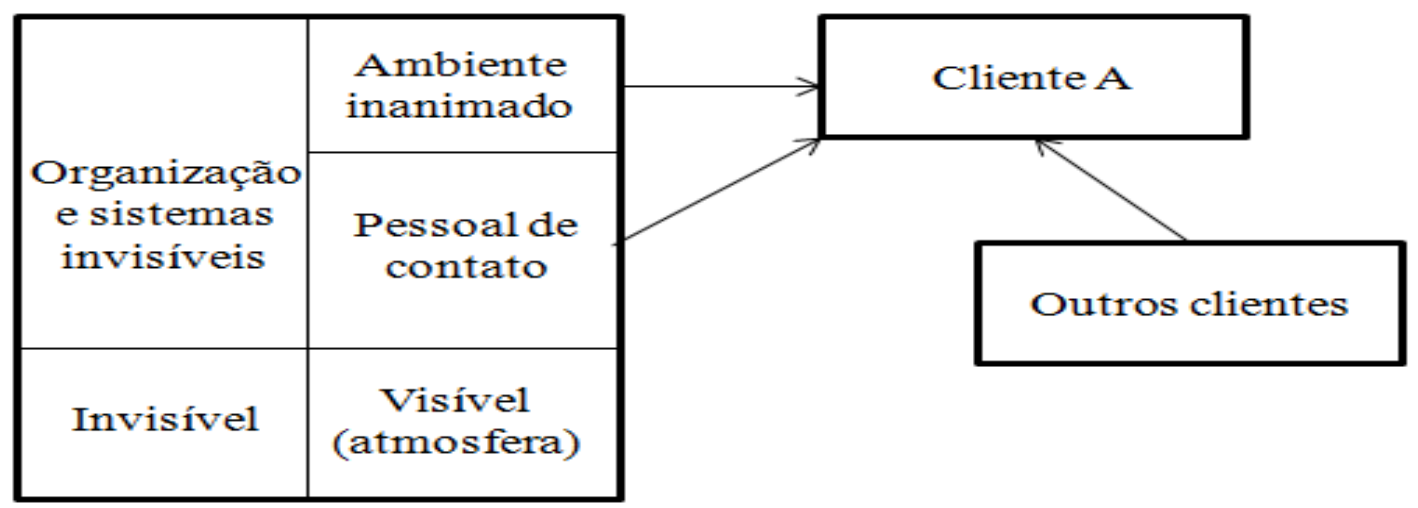

Fonte: adaptado de Langeard, E. et al. (1981). Marketing of services: new insights from consumer and managers. Cambridge, MA: Marketing Sciences Institute, pp. 81-104.

Três fatores são visíveis aos clientes: o ambiente físico de serviços, ou servicescape; os provedores de contato pessoal / serviços e os outros clientes. A organização e os sistemas, embora invisíveis, têm profundo impacto na experiência do cliente.

\subsubsection{MODELO DE DECISÃO DO CLIENTE EM SERVIÇOS}

O modelo do processo de decisão do cliente consiste de três estágios principais: pré-compra, consumo e pós-compra (Hoffman et al., 2009, p. 96). O estágio de pré-compra consiste nos eventos que ocorrem antes da aquisição do serviço pelo cliente e inclui recepção de estímulos, conscientização do problema, busca de informações e avaliação de alternativas. O resultado do estágio de pré-compra é uma decisão que ocorre durante o estágio do consumo.

Segundo este modelo, são atributos para avaliação de serviços pré-compra: (1) atributos de análise, que podem ser determinados antes da compra, (2) atributos de experiência, que somente podem ser determinados durante e após a compra, como simpatia, bom humor, prestativos, etc. e (3) atributos de credibilidade, que são aqueles difíceis de serem avaliados com confiança mesmo após recebimento do bem ou serviço, como qualidade do conserto de um carro, ou o sucesso de uma cirurgia.

Por causa da natureza intangível dos serviços, praticamente não existem atributos de análise para reduzir riscos da compra no estágio de pré-compra. Atributos de credibilidade ganham muita importância para serviços, principalmente por causa da propriedade da inseparabilidade. E, finalmente, por causa da heterogeneidade, serviços são julgados principalmente por atributos de experiência e credibilidade.

Revista Brasileira de Marketing - REMark, São Paulo, v. 12, n. 1, p. 223-250, jan./mar. 2013. 
Num estudo de visão integrada do ambiente de serviços ao processo de decisão, Hoffman e Turley (2002) estudaram o papel das variáveis atmosféricas no encontro de serviço e buscaram endereçar a influência destas variáveis no processo de decisão no consumidor de serviços. De forma conclusiva, defendem que muitos encontros de serviço estão se tornando mais baseados nas instalações e menos baseados nas pessoas dado que poucos provedores de serviços estão disponíveis para emprego, o custo do trabalhador sobe e os avanços na tecnologia promovem automação e o surgimento de nos produtos de serviços.

Em relação ao processo de decisão dos clientes em serviços, os autores estabeleceram os seguintes achados em relação ao estágio pré-compra:

(1) as variáveis atmosféricas aumentam o número de atributos procuráveis disponíveis para produtos de serviço; assim, diminuem o total de risco geralmente associado com as compras de serviços; (2) conforme o total de informação pré-compra diminui, os consumidores colocam mais importância nas variáveis atmosféricas ao estabelecer suas avaliações da qualidade do serviço e (3) à medida que aumentam os efeitos prazerosos com o ambiente de serviço, produzidos pelas variáveis atmosféricas, o total de risco geralmente associado com a compra do serviço diminui. (Hoffman; Turley, 2002, p.37)

Hoffman e Turley (2002) estabelecem ainda achados relevantes em relação ao estágio de consumo:

(1) as variáveis atmosféricas facilitam a categorização dos encontros de serviços; assim, facilitam a seleção de comportamentos de script adequados e aumentam a probabilidade de sucesso na transação de serviço; (2) variáveis atmosféricas facilitam o fluxo do processo de entrega do serviço pela redução da ambiguidade de papéis; assim, aumentam a eficiência e a eficácia potencial do encontro de serviço e (3) variáveis atmosféricas podem gerir eficazmente clientes que compartilham a mesma experiência de serviço simultaneamente; assim, reduzem eficazmente o total de conflitos entre clientes comumente inerentes aos encontros de serviços. (HOFFMAN; TURLEY, 2002, p.38)

\subsection{VAREJO DE SERVIÇOS}

Parente (2010) destaca que o varejo é um dos setores empresariais mais criativos, no qual constantemente temos verificado o surgimento de novos modelos e inovações varejistas. Destaca, entre outros modelos, "hipermercados, lojas de conveniência, locadoras de vídeo, supermercados 24 horas, lojas das empresas telefônicas, como das operadoras paulistas BCP e Telesp Celular." (Parente, 2010, p. 18).

Para o autor, os consumidores passaram a gastar mais em serviços, fruto do aumento da renda per capita nas últimas décadas. Uma ampla gama de atividades varejistas continuará expandindo-se para responder a essas novas necessidades do mercado. Defende que muitas dessas atividades não são imediatamente reconhecidas como varejo; e vai além: propõe que uma análise mais cuidadosa sinalizará suas características varejistas.

Revista Brasileira de Marketing - REMark, São Paulo, v. 12, n. 1, p. 223-250, jan./mar. 2013. 
No tópico a seguir discutem-se as formas pelas quais as variáveis ambientais podem ser manipuladas de forma a criar a atmosfera de varejo adequada para os encontros de serviços.

\subsection{SERVICESCAPES}

Hoffman et al. (2009) definem servicescape como as evidências físicas que envolvem o serviço e ajudam o cliente a avaliá-lo. Consiste em condições do ambiente, como temperatura e música, objetos inanimados que ajudam a empresa a completar suas tarefas, como mobília e equipamento, além de outras evidências físicas, como emblemas, símbolos e artigos pessoais, fotos da família e coleções pessoais. O servicescape cumpre com o papel de empacotar o serviço, facilitar o processo de entrega do serviço, socializar clientes e funcionários e diferenciar a empresa de seus competidores.

Segundo Parente (2000), a imagem que os clientes têm da loja está intimamente ligada à atmosfera que a loja consegue desenvolver. Para tanto as decisões de layout, apresentação e exposição de produtos devem motivar os consumidores a passarem o maior tempo possível na loja.

Essa atmosfera é criada a partir de recursos de apresentação externa e interna da loja, das soluções de layout e a forma de se expor os produtos. Para a criação da atmosfera são utilizados de recursos, como: cores, formas, tamanho da área de venda, decoração, equipamentos de exposição, produtos, comunicação visual, sinalização, sons, aromas e estímulos ao paladar e ao tato; os quais influenciam a visão e outros sentidos dos clientes, e assim, vão construindo sentimentos e emoções para com a loja.

“A atmosfera deve ser entendida como o sentimento psicológico que o varejista desenvolve no consumidor quando ele visita a loja. É também entendida como a personalidade da loja" (Parente, 2000, p. 294).

O ponto de venda é uma das principais formas pela qual um estabelecimento varejista comunica seus propósitos e firma um posicionamento junto ao consumidor. O comportamento do consumidor em uma loja é uma resposta de natureza cognitiva e emocional a estímulos deste espaço físico, permitindo-lhes classificar a empresa frente às suas concorrentes e formular crenças a seu respeito (Smith; Burns, 1996). A apresentação externa da loja provoca o primeiro impacto no consumidor e já sinaliza o tipo de atmosfera que vai encontrar em seu interior.

O ambiente de loja e atmosfera que envolve todo o processo de realização do serviço tem se tornado campo de estudo e aplicação do que se convém hoje nomear Marketing experiencial, tema que será explorado no tópico seguinte.

Revista Brasileira de Marketing - REMark, São Paulo, v. 12, n. 1, p. 223-250, jan./mar. 2013. 


\subsection{MARKETING EXPERIENCIAL}

O Marketing de experiência é apontado por Pontes (2012) como as ações desenvolvidas pelas empresas, junto aos seus clientes, de maneira que eles possam desenvolver os seus cinco sentidos, estimulando-os através de experiências sensoriais. Com isto, a empresa agrega valor para seus clientes e consegue se notabilizar em relação aos seus concorrentes.

Brakus et al. (2009) afirmam que o Marketing de experiência pode ser encarado como as atitudes subjetivas internas e comportamentais do consumidor relacionadas a sua vivência com a marca. Assim, as sensações, sentimentos e cognições do consumidor derivariam, não apenas da identidade da marca, mas da oferta relacionada, da comunicação associada à marca e do ambiente externo. Para eles, o Marketing de experiência pode ocorrer positiva ou negativamente para o consumidor. Ainda pode se dar de forma espontânea (geralmente fugaz) ou de maneira deliberada (mais duradouro). No estudo dos autores, a forte percepção dos consumidores sobre Marketing de experiência estava relacionada aos fatores sensoriais, afetivos, cognitivos e comportamentais de seu relacionamento com a marca, ao passo que a fraca percepção estava associada a eventos de promoção e de redução de preço, como ocorre no varejo em geral.

A experiência, segundo Ma (2009), é o sentimento mais perfeito e profundo que surge nos consumidores quando eles estão completamente envolvidos no processo de consumo a partir de uma situação criada pela empresa. O Marketing de experiência, então, seria a tentativa da empresa de incentivar a aquisição de seus produtos através da experiência de consumo de seus clientes, levando-os a conhecer e a interagir com os produtos. Os executivos de Marketing devem estar atentos a esta nova abordagem, devendo incorporar aspectos relacionados ao novo padrão de consumo que contemplem cinco variáveis principais: sentidos do consumidor, sensibilidade, pensamento, ação e associação.

Esta abordagem nova coloca o consumidor como um ser racional e emotivo, e sua experiência antes, durante e após o consumo deve ser considerado um fator relevante para se analisar o comportamento do consumidor e o gerenciamento da marca. Neste ínterim, Pontes (2012) afirma que os produtos não são percebidos pelos consumidores, apenas, como pressupostos individuais objetivos, mas, antes de tudo, como signos carregados de subjetividade.

O Marketing de experiência permite que a empresa reforce sua capacidade de lucro ao permitir a customização da oferta, serviços adicionais, qualidade superior, tudo isto em detrimento do preço baixo como sinônimo de competitividade. Ao contrário, a empresa consegue um preço prêmio pelo nível de excelência de seus produtos. O Marketing de experiências deve ser o padrão

Revista Brasileira de Marketing - REMark, São Paulo, v. 12, n. 1, p. 223-250, jan./mar. 2013. 
de medida da satisfação do cliente, do seu sentimento, pois ele introduz a marca pelas ações, mantém e desenvolve recursos para os clientes da empresa e cumpre as promessas endereçadas aos seus consumidores.

As experiências agradáveis para os consumidores devem ser criados pelas empresas (MA, 2009), pois o Marketing de experiências permite a construção de significados simbólicos associados ao consumo. Isto é, amplia a visão do consumidor sobre o evento de consumo: o consumidor pode associar uma determinada marca a experiências anteriores vivenciadas por ele (Pontes, 2012).

Neste sentido, Brakus et al. (2009) e Ma (2009) advogam que o Marketing de experiência impacta direta e indiretamente a satisfação do consumidor e sua lealdade à marca por intermédio da personalidade da marca e suas associações. Com a demanda por produtos ancorada em fatores racionais e emotivos, os clientes podem se sentir tentados à manutenção do relacionamento com a empresa, pois eles desejariam mais experiências e comunicação providas pela empresa. O Marketing de experiências deve satisfazer plenamente as demandas dos consumidores, considerando suas experiências como uma diretriz para conceber, produzir, distribuir e oferecer serviços complementares, tornando-o fiel à empresa.

Pine e Gilmore (1998) propõem o "Modelo de hierarquia do local", em que são apontados cinco níveis que apontam como e onde as empresas podem criar eventos de experiências para serem desfrutados por seus clientes. Segundo oeste autores, embora a empresa não possa realizar tudo em todos os locais, ela deve definir em quais deles ela pode maximizar as vantagens decorrentes das atividades do Marketing de experiências. Os níveis são:

1. Local emblemático: corresponde ao local singular, inexoravelmente associado à empresa, onde ela realiza as melhores e mais dinâmicas experiências para seus clientes. Aqui, a empresa propicia aos seus clientes uma experiência singular criada a partir de seu patrimônio e consegue expandir suas ofertas, gerando, assim, novas fontes de receitas.

2. Centros de experiência: alguns locais em que a população normalmente converge, como centros de turismo. Dependendo da área de negócios da empresa, ela poderá estar situada em cidades com aquele perfil.

3. Locais principais: local onde a maioria das empresas instalam seus primeiros pontos de venda. Este local deve contar com uma população grande o suficiente para justificar este atendimento.

Revista Brasileira de Marketing - REMark, São Paulo, v. 12, n. 1, p. 223-250, jan./mar. 2013. 
4. Presença secundária: a empresa pode aparecer em um local ou evento cuja propriedade seja de outra companhia. Ela deve se aproveitar das riquezas de experiência geradas por estes lugares para criar uma forma de relacionamento com seus prospects.

5. Mercados mundiais: esta é uma forma dos clientes potenciais poderem encontrar as ofertas das empresas perto de onde moram. Para os fabricantes, além de favorecer a experimentação do produto, também permite o Marketing de experiências. Para os provedores de serviços, é importante transformar cada interação, ainda que inoportuna, em uma experiência.

Pine e Gilmore (1998) mostram ainda que conceituadas empresas, como Disney e Warner, gigantes do entretenimento, fracassaram em suas incursões pelo varejo, ao adotarem modelos antiquados de lojas, desconsiderando uma oportunidade ímpar de criarem experiências no varejo para atrair clientes potenciais. Diferentemente, a Pleasant Company (adquirida, posteriormente, pela Mattel, no ano de 2002) tradicional fabricante americana de brinquedos, insere diversas atrações para as crianças e suas mães de divertirem, o que torna a experiência de comprar extremamente prazerosa.

Os autores apontam, ainda, que a visão tradicional de Marketing exercida por muitas empresas no que tange aos seus relacionamentos está em declínio, em grande parte pela fragmentação do mercado, pela ineficiência das mídias tradicionais e, também, pela forma, aparentemente falha, como as empresas utilizam a Internet para se comunicar com seus prospects. A solução para este problema, de acordo com os mesmos, reside em as empresas criarem experiências que envolvam seus clientes.

\subsection{TENDÊNCIAS VAREJISTAS}

Parente (2010) destaca, entre as principais tendências que vêm impulsionando a transformação no varejo: aumento da globalização, aumento da consolidação de empresas, aumento do poder do varejo, parceria e alianças com fornecedores, polarização: massificação vs. especialização, aumento da concorrência de formatos substitutos, tecnologia da informação, capital humano e profissionalização, novos formatos e composições varejistas, expansão do varejo sem lojas, varejo virtual, aumento do varejo de serviços, maior foco no cliente e Marketing de relacionamento, mudanças no comportamento do consumidor, aumento do sistema de autosserviço,

Revista Brasileira de Marketing - REMark, São Paulo, v. 12, n. 1, p. 223-250, jan./mar. 2013. 
mudanças nas características do mercado brasileiro e migração das classes ABC para centros de compras planejados e shoppings.

Corroborando a maioria dos pontos colocados por Parente (2010), o instituto de pesquisas Ipsos, por meio de sua área especializada em varejo Ipsos Shopper \& Retail, apresenta um importante estudo que traça o panorama das tendências mundiais para o setor. Por meio de um conjunto de informações reunidas em congressos como o National Retail Federation, do contato com especialistas do setor e de visitas realizadas nos mercados americano e inglês, nos meses de janeiro e fevereiro de 2008, foram identificadas sete tendências:

\section{$\checkmark \quad$ Negócios Verdes}

Esta tendência está diretamente relacionada à sustentabilidade. É preciso entender que não basta mais ter um produto correto; todo o processo precisa estar em paz com a natureza, reduzindo os impactos, o consumo de energia e poluindo menos. Ser verde é ser correto.

\section{$\checkmark \quad$ Varejo Global em Expansão}

A globalização fez aumentar a concentração de poder do varejo. E este poder vem sendo determinante na tomada de decisões tanto em relação à indústria quanto ao consumidor, contribuindo para fortalecimento do varejo organizado.

\section{$\checkmark \quad$ Cauda Longa}

Os produtos estão cada vez mais parecidos entre si e os consumidores cada vez mais exigentes no momento da compra. Valor agregado passou a ser mais importante que preço. Marcas e produtos, mesmo os líderes, que não conseguirem se diferenciar, tendem a se transformar em commodity.

\section{$\checkmark \quad$ Foco na Experiência}

Comprar não é mais um gesto isolado. Agora o momento da compra está carregado de emoção e o consumidor quer ser feliz no ponto de venda. Os valores relacionados ao "ter" estão migrando para o "ser". O produto é adquirido por seu valor emocional e não somente por seu valor financeiro.

\section{$\checkmark \quad$ Varejo de Decisão e Experimentação}

O consumidor busca novidades e é no ponto de venda que ele deseja experimentar e conhecer novos produtos e marcas. O varejo deve funcionar como mídia e ser o palco para a comunicação das marcas.

Revista Brasileira de Marketing - REMark, São Paulo, v. 12, n. 1, p. 223-250, jan./mar. 2013. 


\section{$\checkmark \quad$ Investimento em Serviços - Solution Centric Retail}

O varejo é um player muito poderoso. Primeiro, consolidou suas marcas próprias e agora o setor investe em serviços passando a avalizar outros serviços, como a venda de seguros, de viagens e food service.

\section{$\checkmark \quad$ Integração Multicanal}

O varejo precisa estar integrado com todas as demandas de compra do consumidor, que busca informações em diversas fontes. Diante dessa demanda loja física, virtual, catálogos devem funcionar em sintonia.

\subsection{MERCADO DE TELECOMUNICAÇÕES BRASILEIRO E A VIVO}

Segundo Pires (1999), a formação do setor de telecomunicações no Brasil respondeu ao novo contexto de globalização econômica, de evolução tecnológica setorial, de novas exigências de diversificação e modernização das redes e dos serviços, além de permitir a universalização da prestação de serviços básicos, tendo em vista a elevada demanda reprimida no país.

Este setor, após o processo de privatização ocorrido na década de 90, passou a ser o responsável pelo provimento do serviço de comunicação a toda a população brasileira, regulamentado pela Agência Nacional de Telecomunicações (Anatel).

Diversas novas empresas surgiram em todo o território brasileiro para substituir o Estado, com a promessa de inovação e melhores níveis de qualidade na prestação do serviço. Novas formas de relacionamento entre cliente e empresa foram estabelecidas e o envolvimento do consumidor com a avaliação do serviço de telecomunicação passou a ser cada vez mais relevante. A concorrência entre empresas num mesmo mercado consumidor aumentou e, questões, como 'marca, posicionamento e oferta' tornaram a atividade do profissional de Marketing do setor mais desafiadora.

No passado, o telefone celular foi considerado um objeto de luxo, um bem valioso, raro e escasso. Após a privatização, com a popularização do serviço, principalmente com a introdução do serviço pré-pago, em 1998, o celular passa a se tornar inclusive uma alternativa à telefonia fixa, para pessoas de todas as classes sociais, trazendo para as marcas diversos perfis de clientes.

Com o tempo, "o mercado baseado na aquisição de novos clientes (que não possuíam telefone celular) se transformou num mercado de captação de clientes da concorrência, sobretudo os de maior valor: os clientes pós-pagos. Isso provocou grande movimentação no sentido de fidelizar a base de clientes" (Sato, 2010, p. 59).

Revista Brasileira de Marketing - REMark, São Paulo, v. 12, n. 1, p. 223-250, jan./mar. 2013. 
Do ponto de vista das marcas atuantes, até o início dos anos 2000, o mercado brasileiro era formado por marcas locais, com atuação em estados ou regiões específicas do país. O panorama foi alterado rapidamente com a consolidação de um cenário formado por quatro grandes marcas de atuação nacional: Claro, Oi, TIM e Vivo.

Atualmente, o mercado de telecomunicação móvel brasileiro apresenta densidade acima de $100 \%$, alcançando em junho/2012 a marca de 130\%, o que representa sua relevância no mercado econômico brasileiro: é maior o número de linhas celulares em operação que o número de habitantes no Brasil. O tamanho do mercado (móvel) hoje é de mais de 256 milhões celulares, dividido nas seguintes cotas de mercado entre as operadoras, com dados da Anatel, relativos a maio/2012: VIVO, 29,63\%; TIM, 26,88\%, Claro, 24,59\%; e Oi 18,65\%.

A VIVO é a marca comercial que representa os serviços de telecomunicação prestados no Brasil pelo grupo espanhol Telefônica. A VIVO foi lançada em 2003 a partir de uma joint venture para formar a maior comunidade de clientes do Brasil. A proposta da marca, de acordo com o site da empresa, é oferecer produtos e serviços de comunicação, trazendo inovações e vantagens para tornar o dia-a-dia de seus clientes mais fácil e divertido.

Como informa o site da operadora, hoje a Vivo atende a mais de 90 milhões de clientes. A missão da marca VIVO é “Ampliar as possibilidades de conexões entre as pessoas para que possam viver de forma mais humana, segura, inteligente e divertida, em todos os seus papeis.”. Entre os principais produtos e serviços ofertados pela operadora estão: telefonia fixa, telefonia móvel (voz, dados e internet), internet banda larga fixa e TV, além da venda de aparelhos como celulares, smartphones, modens e adaptadores.

\section{MÉTODO}

Este artigo será desenvolvido na forma de um estudo descritivo. De acordo com Sampieri et al. (2006), os estudos descritivos procuram especificar as propriedades, as características e os perfis importantes de pessoas, grupos, comunidades ou qualquer outro fenômeno que se submeta à análise. Eles medem, avaliam ou coletam dados sobre diversos aspectos, dimensões ou componentes do fenômeno a ser pesquisado (p. 101).

Para discussão do tema proposto, serão utilizadas duas formas de pesquisa: (1) a bibliográfica, (Cooper; Schindler, 2004), que oferece meios para definir, resolver, não somente problemas já conhecidos, como também explorar novas áreas onde os problemas não se cristalizaram suficientemente; e (2) a netnografia (Kozinets, 2007), com uma breve pesquisa de campo, considerando uma operadora de telecomunicações do Brasil (Vivo).

Revista Brasileira de Marketing - REMark, São Paulo, v. 12, n. 1, p. 223-250, jan./mar. 2013. 
A pesquisa documental trata da coleta de dados, restrita a documentos, escritos ou não, constituindo o que se denomina de fontes primárias, que podem ser feitas no momento em que o fato ou fenômeno ocorre, ou depois. A netnografia faz uso da web com o intuito de ampliar o leque epistemológico dos estudos em comunicação e cibercultura e nas ciências sociais aplicadas (Amaral, 2008; Kozinets, 2007).

Assim, para a consecução dos objetivos deste trabalho, procede-se ao desenvolvimento de revisão teórica dos temas relevantes, nomeadamente as práticas do Marketing de Serviços, Varejo e do Marketing Experiencial, para de forma tentativa, estabelecer relações e contribuições tanto no campo teórico como no campo da prática, fomentando a reflexão e discussão no tema.

\section{PESQUISA DE CAMPO - LOJA CONCEITO VIVO}

A loja conceito Vivo, situada no Morumbi Shopping, em São Paulo, foi desenvolvida durante o ano de 2009 e aberta ao público ao final do ano de 2009. Segundo informações internas, a loja foi concebida com o desafio de "reinventar o conceito de loja da Vivo, alinhado à nova estratégia e posicionamento da marca, proporcionando ao consumidor contato com os ideais de sociedade em rede e sustentabilidade e criando uma relação de confiança e fidelidade."

O espaço abrange um ambiente interativo de $170 \mathrm{~m}^{2}$, onde a operadora oferece atendimento consultivo com horário agendado e livre degustação de produtos e serviços. O projeto aponta que foi realizada uma revisão da estética e funcionalidade da loja, seguindo a identidade visual da marca. A proposta privilegia a fachada sem vitrine e com grande vão de entrada: a defesa traz a ideia de que a própria loja é o atrativo. Alinhado ao valor da sustentabilidade, o espaço foi construído com materiais sustentáveis, como expositores plásticos recicláveis, mobiliário de madeira certificada e iluminação LED.

Revista Brasileira de Marketing - REMark, São Paulo, v. 12, n. 1, p. 223-250, jan./mar. 2013. 
Figura 2: Fachada da loja conceito Vivo.

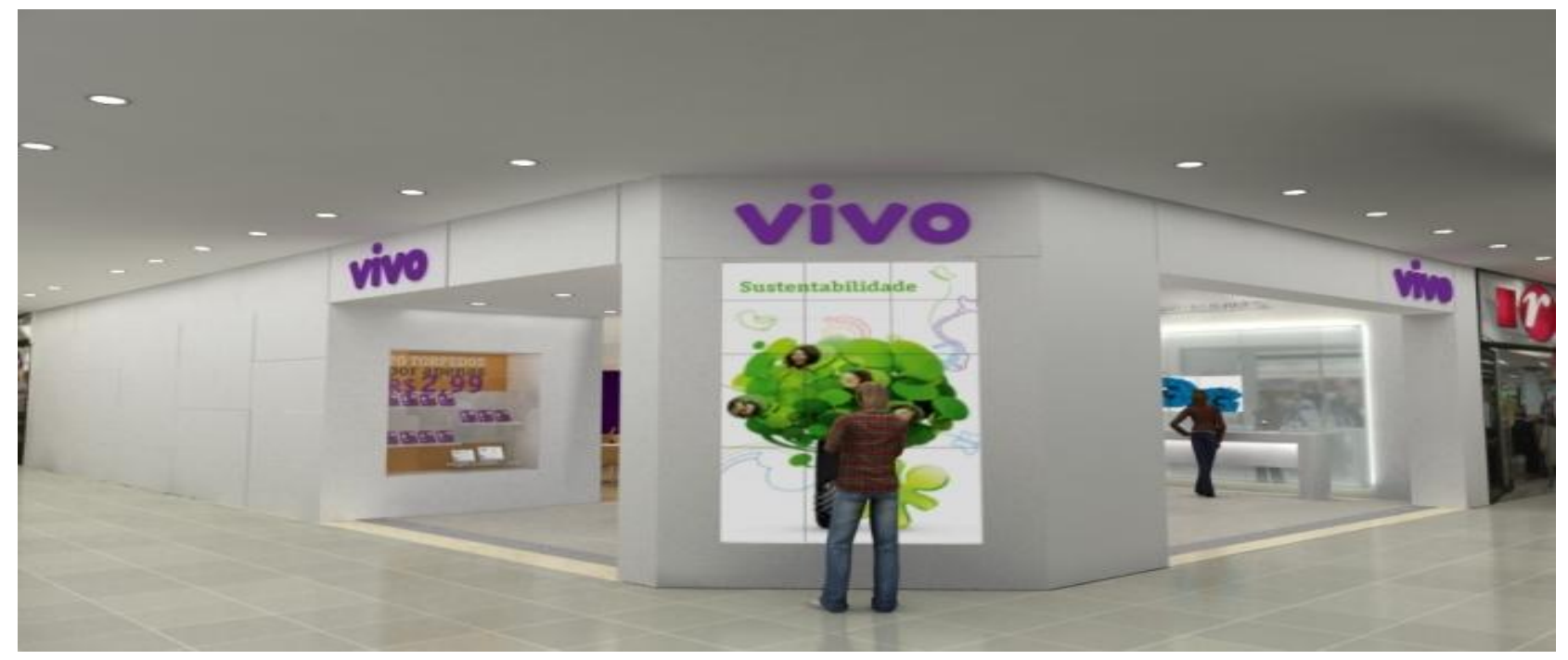

A iluminação do ponto de venda conta com a tecnologia LED que usa menos energia e dura mais. Nas paredes, há o uso de tintas ecologicamente corretas. Materiais reciclados também foram utilizados no forro do teto e implantação de madeira certificada no chão.

Figura 3: Interior da loja conceito Vivo.

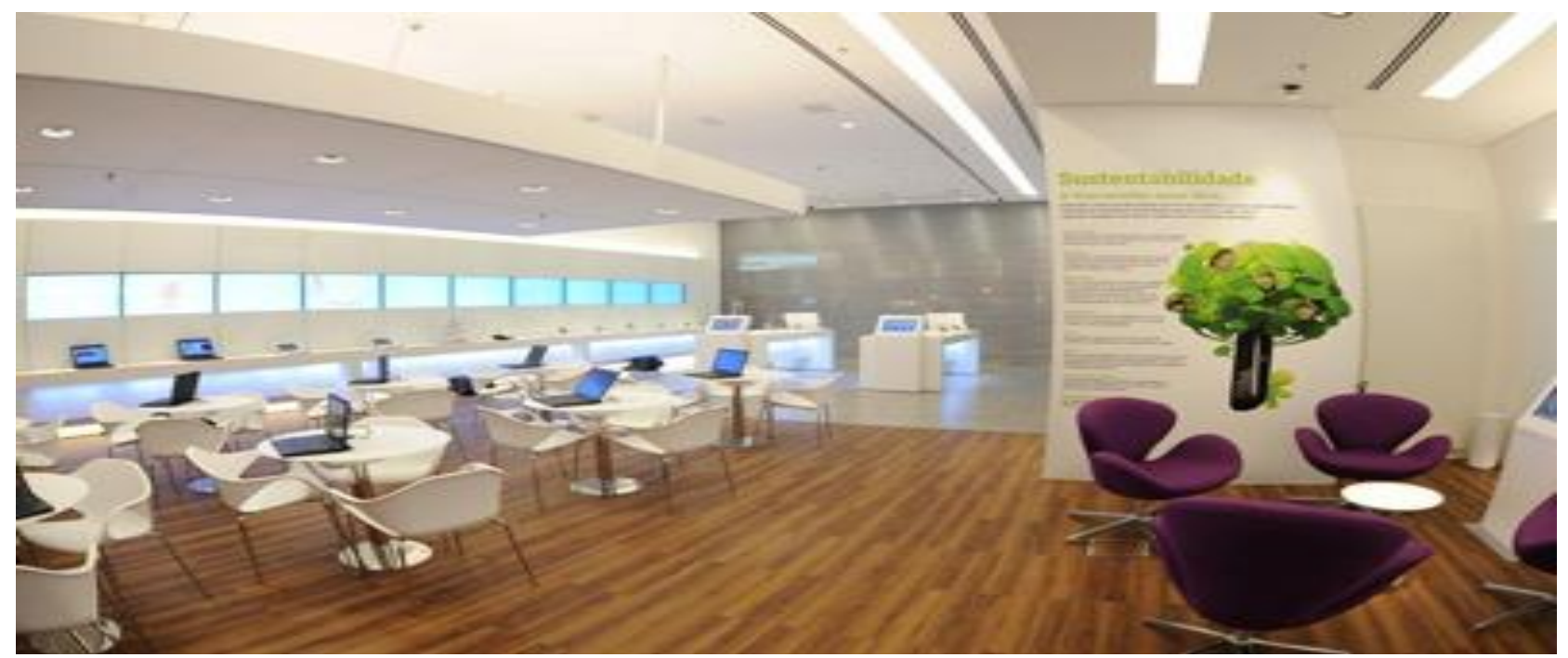

O espaço também propõe uma nova forma de merchandising, a partir dos conceitos de sustentabilidade, interatividade e tecnologia limpa. A ideia foi utilizar o formato de informações digitais para estabelecer uma comunicação diferenciada: informando, educando e entretendo. Além disso, o merchandising digital economiza papel, tintas e outras matérias primas.

O projeto considera um conjunto de pontos de contatos digitais que permitem a interatividade total com conteúdos dinâmicos, como vídeos, gráficos e animações. Através de uma interface flexível e simplificada, o consumidor pode personalizar conteúdos em tempo real, de acordo com suas preferências.

Revista Brasileira de Marketing - REMark, São Paulo, v. 12, n. 1, p. 223-250, jan./mar. 2013. 
Figura 4: Interfaces digitais de comunicação na loja conceito Vivo.
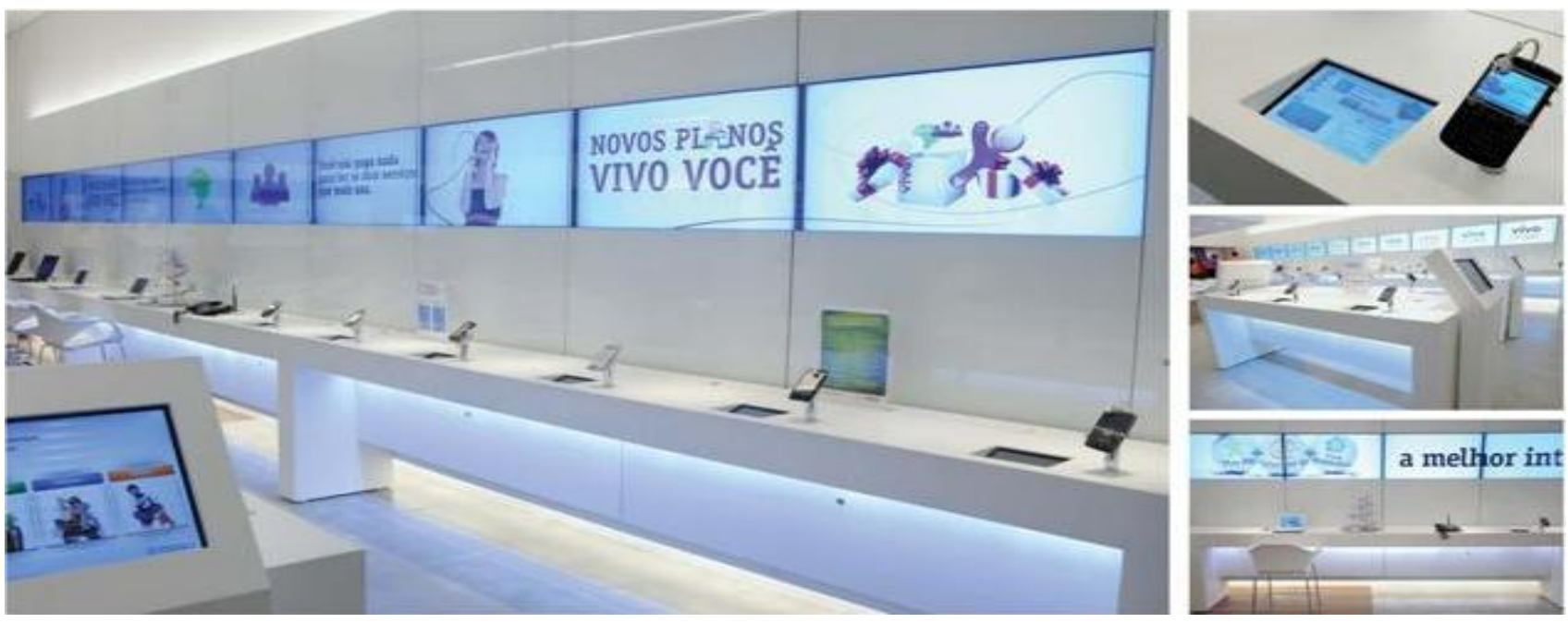

Além da inovação tecnológica e sustentável, o novo modelo propõe uma evolução no modelo de atendimento e relacionamento com o cliente: com o objetivo de tornar as vendas mais consultivas, o que é incomum no mercado de telecomunicações, a linha de balcão contínua foi substituída por mesas individuais com um atendimento mais personalizado - o processo de venda acontece em todo o salão da loja.

Figura 5: Área de atendimento da loja conceito Vivo.
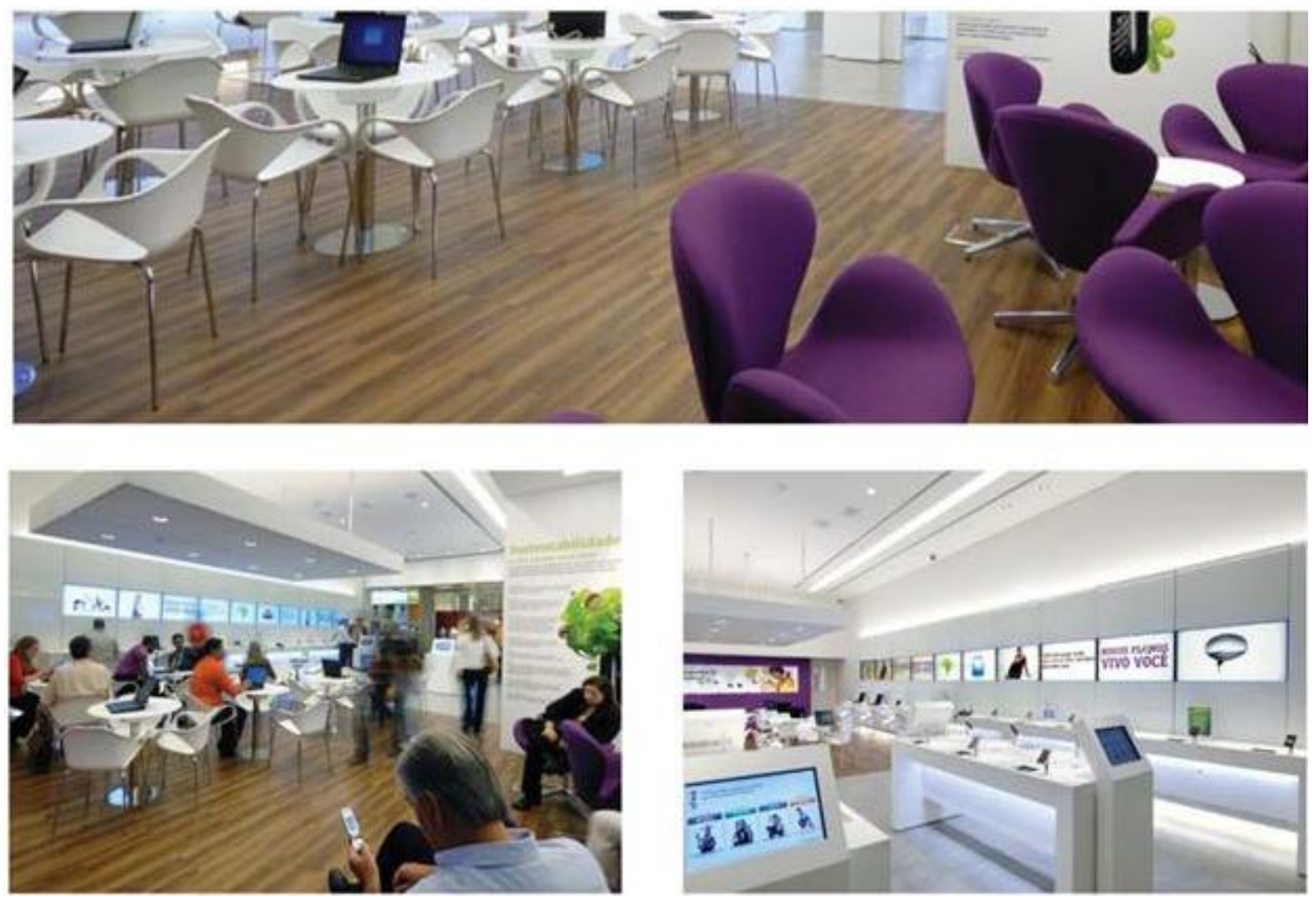

Revista Brasileira de Marketing - REMark, São Paulo, v. 12, n. 1, p. 223-250, jan./mar. 2013. 
Com isso, a área de espera prioriza o conforto e o ambiente destinado para a divulgação de serviços e treinamentos ficou maior e mais relevante. Além disso, um novo modelo de atendimento foi introduzido, a fim de se reduzir o tempo de espera e aumentar a satisfação dos clientes. A área de autoatendimento foi idealizada independente da loja e disponível para os clientes durante todo o horário de funcionamento do shopping, à semelhança dos terminais bancários de autoatendimento.

Em suma, uma breve avaliação do projeto sugere a reinvenção da experiência de compra da categoria de telecomunicações e inclusive da própria marca Vivo, no sentido de estimular o consumidor a experimentar uma vida mais conectada.

O Quadro 1 baseada na concepções de Gröonroos (1995) apresenta as características distintivas dos serviços, os problemas de Marketing que delas decorrem, possíveis formas de minimização destes problemas por meio do desempenho de ações relacionadas ao Marketing experiencial e finalmente, uma exemplificação da pesquisa de campo realizada na loja conceito Vivo:

\begin{tabular}{|c|c|c|c|c|}
\hline $\begin{array}{l}\text { CARACTERÍ́STICAS } \\
\text { DISTINTIVAS DOS } \\
\text { SERVIÇOS }\end{array}$ & $\begin{array}{c}\text { COMO O } \\
\text { MARKETING } \\
\text { EXPERIENCIAL } \\
\text { PODE MINIMIZAR O } \\
\text { IMPACTO DESTE } \\
\text { PROBLEMA? }\end{array}$ & $\begin{array}{l}\text { DESCRIÇão DA } \\
\text { CARACTERÍSTICA } \\
\text { DISTINTIVA }\end{array}$ & $\begin{array}{c}\text { EXEMPLIFICAÇÃO } \\
\text { DA PESQUISA DE } \\
\text { CAMPO - LOJA } \\
\text { CONCEITO VIVO }\end{array}$ & PROBLEMAS DECORRENTES \\
\hline Intangibilidade & $\begin{array}{c}\text { Por serem } \\
\text { intangíveis, os } \\
\text { serviços não podem } \\
\text { ser vistos, sentidos, } \\
\text { degustados ou } \\
\text { tocados. }\end{array}$ & $\begin{array}{l}\text { Torna difícil a } \\
\text { avaliação dos } \\
\text { serviços pelos } \\
\text { usuários antes de } \\
\text { sua realização. }\end{array}$ & $\begin{array}{c}\text { As sensações } \\
\text { propiciadas pelo } \\
\text { Marketing } \\
\text { experiencial ajudam } \\
\text { os usuários de } \\
\text { serviços a preverem } \\
\text { um nível de } \\
\text { qualidade percebida } \\
\text { elevada, antes } \\
\text { mesmo da execução } \\
\text { dos mesmos. }\end{array}$ & $\begin{array}{c}\text { O projeto de loja, mais } \\
\text { convidativo e com visual mais } \\
\text { impactante sugere níveis } \\
\text { diferenciados de qualidade. O } \\
\text { alto nível de experiência } \\
\text { sensorial percebida na loja } \\
\text { (telões, experimentação de } \\
\text { serviços e manipulação), } \\
\text { contribui para aumentar a } \\
\text { tangibilidade da prestação de } \\
\text { serviço. Pontos específicos, } \\
\text { como a preocupação com o uso } \\
\text { de materiais sustentáveis, estão } \\
\text { em linha com as tendências } \\
\text { varejistas estudadas e ajudam a } \\
\text { reduzir a intangibilidade e maior } \\
\text { “frieza” do aspecto tecnológico. }\end{array}$ \\
\hline
\end{tabular}

Revista Brasileira de Marketing - REMark, São Paulo, v. 12, n. 1, p. 223-250, jan./mar. 2013. 


\begin{tabular}{|c|c|c|c|c|}
\hline Inseparabilidade & $\begin{array}{c}\text { Está relacionada ao } \\
\text { vínculo físico do } \\
\text { prestador do serviço } \\
\text { com o serviço em } \\
\text { si, ao envolvimento } \\
\text { do cliente na } \\
\text { produção do } \\
\text { serviço, além do } \\
\text { envolvimento de } \\
\text { outros } \\
\text { fornecedores. }\end{array}$ & $\begin{array}{l}\text { A presença, } \\
\text { muitas vezes } \\
\text { essencial, do } \\
\text { usuário dos } \\
\text { serviços pode } \\
\text { comprometer o } \\
\text { resultado dos } \\
\text { mesmos, } \\
\text { dependendo do } \\
\text { grau de sua } \\
\text { interferência. }\end{array}$ & $\begin{array}{c}\text { O Marketing } \\
\text { experiencial torna } \\
\text { os usuários mais } \\
\text { receptivos à } \\
\text { cooperação com os } \\
\text { prestadores dos } \\
\text { serviços. }\end{array}$ & $\begin{array}{c}\text { A presença e participação do } \\
\text { cliente no processo de prestação } \\
\text { de serviço podem ser } \\
\text { consideradas uma premissa do } \\
\text { projeto, uma vez que o conceito } \\
\text { de loja interativa privilegia o } \\
\text { cliente como condutor da } \\
\text { experiência. O cliente escolhe o } \\
\text { horário em que deseja ser } \\
\text { atendido, tem um atendimento } \\
\text { consultivo e personalizado, além } \\
\text { de poder contar com um } \\
\text { especialista que o orienta e } \\
\text { capacita no uso das tecnologias. }\end{array}$ \\
\hline Heterogeneidade & $\begin{array}{c}\text { Refere-se à } \\
\text { variação na } \\
\text { realização de uma } \\
\text { mesma transação de } \\
\text { serviço. }\end{array}$ & $\begin{array}{l}\text { A incapacidade } \\
\text { de controlar a } \\
\text { qualidade do } \\
\text { serviço prestado }\end{array}$ & $\begin{array}{c}\text { O Marketing } \\
\text { experiencial } \\
\text { permite que cada } \\
\text { cliente possa ter } \\
\text { uma experiência } \\
\text { customizada, o que } \\
\text { se traduz em uma } \\
\text { forma de } \\
\text { diferenciação dos } \\
\text { serviços. }\end{array}$ & $\begin{array}{l}\text { A mudança no formato de } \\
\text { atendimento, do tradicional } \\
\text { "balcão" das operadoras de } \\
\text { telecomunicações para o formato } \\
\text { "salão", tornou o atendimento } \\
\text { mais próximo e personalizado, } \\
\text { priorizando a relação entre o } \\
\text { cliente e a marca. }\end{array}$ \\
\hline Perecibilidade & $\begin{array}{l}\text { Os serviços não } \\
\text { podem ser } \\
\text { estocados para uso } \\
\text { futuro. }\end{array}$ & $\begin{array}{l}\text { A incapacidade } \\
\text { de se adequar } \\
\text { imediatamente à } \\
\text { demanda. }\end{array}$ & $\begin{array}{c}\text { O Marketing } \\
\text { experiencial buscar } \\
\text { fidelizar os clientes } \\
\text { e homogeneizar a } \\
\text { demanda ao longo } \\
\text { do tempo. }\end{array}$ & $\begin{array}{l}\text { Os diferenciais de atendimento } \\
\text { com horário agendado e o } \\
\text { conjunto de ferramentas } \\
\text { interativas a dispor dos clientes } \\
\text { são exemplos das ferramentas } \\
\text { que permitem à marca gerenciar } \\
\text { melhor a demanda, bem como } \\
\text { tratar melhor o tempo de espera. }\end{array}$ \\
\hline
\end{tabular}

Quadro 1: Amarração dos temas e exemplificação.

Fonte: criado pelos autores.

Revista Brasileira de Marketing - REMark, São Paulo, v. 12, n. 1, p. 223-250, jan./mar. 2013. 


\section{CONCLUSÕES E CONSIDERAÇÕES FINAIS}

Nesta etapa final de estudo, propõe-se uma amarração teórico/ prática, que ao mesmo tempo, relaciona os temas tratados na esfera teórica e exemplifica a questão por meio da pesquisa de campo realizada.

Conclui-se, pelo exposto nos tópicos anteriores, que o Marketing experiencial pode, de uma forma bastante eficaz, abrandar as características distintivas dos serviços que os tornam, muitas vezes, de difícil gerenciamento. A consideração da prestação de serviços como de fato uma relação que acontece, no seu nível mais estreito, no ponto de venda, coloca o foco da discussão no âmbito da lógica varejista.

Este artigo nos permite apontar que o estudo do Marketing experiencial, apesar de insipiente, começa a originar um corpo teórico substancial. Neste sentido, percebemos uma série de definições, muitas vezes antagônicas ou com sentidos bastante díspares, o que não permite uma consolidação do tema. Outro ponto a se destacar é que os estudos pouco mostram sobre os efeitos adversos que uma experiência mal sucedida do cliente com a marca pode ocasionar. Na verdade, trata-se de uma forma maniqueísta de alguns autores que, no afã de consolidarem o conceito do Marketing de experiências, procuram reduzi-lo aos aspectos somente positivos de sua implantação.

O estudo bibliográfico tem como limitação o fato de se dispor de muitas informações que acabam por se perder em virtude da escassez de tempo para sua coleta. Também propicia certo viés por se centrar, apenas, na expectativa do pesquisador, de acordo com seus humores.

Pesquisas poderiam ser realizadas a fim de se produzirem escalas de avaliação para os aspectos de consumo relacionados ao uso dos sentidos. Neste sentido, alguns ensaios já começam a ser ensaiados por Schmitt (2002).

Mais estudos de casos poderiam ser feitos para efeito de comparação tanto em termos de abordagem quanto do uso do Marketing de experiências pelas empresas.

Revista Brasileira de Marketing - REMark, São Paulo, v. 12, n. 1, p. 223-250, jan./mar. 2013. 


\section{REFERÊNCIAS}

Amaral, A. (2008). Autonetnografia e inserção online. O papel do pesquisador-insider nas subculturas da web. In: Anais do GT Comunicação e Sociabilidade do XVII Encontro Anual da Compós. São Paulo.

Blessa, R. (2005). Merchandising no ponto de venda. $3^{\text {a }}$ ed. São Paulo: Atlas.

Brakus, J. J; Schmitt, B. H; Zarantonello, L. (2009). Brand experience: What is it? How is it measured? Does it affect loyalty? Journal of Marketing, v. 73, pp. 52-68.

Cooper, D. R.; Schindler, P. S. (2004). Métodos de pesquisa em Administração. 7th ed. Porto Alegre: Bookman.

Da Rocha, A.; Ferreira Da Silva, J. (2006). Marketing de serviços: retrospectiva e tendências. Rev. adm. empres. [online]. v. 46, n. 4, pp. 1-9.

Dagger, T. S.; O'brien, T. K. (2010). Does experience matter?: Differences in relationship benefits, satisfaction, trust, commitment and loyalty for novice and experienced service users. European Journal of Marketing,v. 44. N. 9/10, pp. 1528-1552.

Fornell, C. A. (January, 1992). National Customer Satisfaction Barometer: The Swedish Experience. Journal of Marketing, v.56, pp. 6-21.

Grönroos; C. (1995). Marketing: gerenciamento e serviços: a competição por serviços na hora da verdade. Rio de Janeiro: Campus.

Han, S.; Sun, X. Feb. (2012). On the Experience Marketing Strategies of Maky Food Company. Asian Social Science Vol. 8, No. 2.

Hoffman, K. D.; Bateson, J. E. G.; Campomar, M. C.; Ikeda, A. A. (2009). Princípios de Marketing de serviços: conceitos, estratégias e casos. São Paulo: Cengage Learning.

; Turley, L. W. (summer 2002). Atmospherics, service encounters and consumer decision making: An integrative perspective. Journal of Marketing Theory and Practice, n. 10, pp. 33-47.

Kotler P.; Keller, K. L. (2006). Administração de Marketing. São Paulo: Pearson Prentice Hall.

Kozinets, R. V. (2007). Netnography 2.0. In: R. W. Belk, Handbook of Qualitative Research Methods in Marketing . Edward Elgar Publishing.

Las Casas, A. L. (2000). Marketing de serviços. 2. ed. São Paulo: Atlas.

Revista Brasileira de Marketing - REMark, São Paulo, v. 12, n. 1, p. 223-250, jan./mar. 2013. 
Lovelock, C.; Wright, L. (2001). Serviços: Marketing e Gestão. São Paulo: Saraiva.

Ma, J. (dec. 2009). Embedded Study on the Experience Marketing from Consumers. View. International Journal of Business and management, v. 4, n. 12, pp. 146-152.

Narver, J. C.; Slater, S. F. (1990). The effect of a market orientation on business profitability. Journal of Marketing, v. 54, n. 4, pp. 20-35.

Parasuraman, A.; Zeithaml, V. A.; Berry, L. (1985). A conceptual model of service quality and its implications for future research. Journal of Marketing. USA, v. 49, n. 4, pp. 41-50, fall.

Parente, J. (2010). Varejo no Brasil. Gestão e Estratégia. $1^{a}$ ed. São Paulo: Atlas.

Pine Ii, B. J.; Gilmore, J. H. (Jul-Aug, 1998). Welcome to the experience economy. Harvard Business Review.

Pires, J. C. L. (1999). A reestruturação do setor de telecomunicações no Brasil. Revista do BNDES, n. 11.

Pontes, M. C. (2012). Marketing experiencial ou o uso da experiência no Marketing? Estudo de caso em hotéis 5 estrelas da cidade de São Paulo. Tese (Doutorado em Administração) Faculdade de Economia, Administração e Contabilidade, Universidade de São Paulo, São Paulo, 2012. Disponível em: <http://www.teses.usp.br/teses/disponiveis/12/12139/tde11062012-200639/>. Acesso em: 2012-05-25.

Sampieri, R. H.; Collado, C. F.; Lucio P. B. (2006). Metodologia de pesquisa. $3^{\text {a }}$ ed. São Paulo: McGraw-Hill.

Sato, S. K. (2010). As expressões da mobilidade na comunicação das marcas de telefonia celular no Brasil. Tese de Mestrado entregue à EAC-USP. São Paulo.

Schmitt, B. H. (2002). Marketing experimental/ Bernd H. Schmitt (tradução Sara Gedanke). São Paulo: Nobel.

Smith, P.; Burns, D. J. (1996). Atmospherics and retail environments: the case of the power aisle. International Journal of Retailing \& Distribution Management. USA, 24 (1), pp. 7-14.

Zeithaml, V. A.; Bitner, M. J. (2003). Marketing de Serviços: a empresa com foco no cliente. Porto Alegre: Bookman.

Zolfagharian, M. (2007). An exploratory investigation of the effects of co-production and coconsumption on the characteristics and adoption of service innovations: the customer's perspective. EUA, 2007, 178 p. Tese (Doutorado em Filosofia). University of North Texas.

Revista Brasileira de Marketing - REMark, São Paulo, v. 12, n. 1, p. 223-250, jan./mar. 2013. 
Webgrafia:

Portal Anatel. Disponível em http://www.anatel.gov..br. Acessado em 05/08/2012.

Site instituto Ipsos. Release da assessoria de imprensa do instituto de pesquisas Ipsos. Tendências do Varejo. Disponível em http://www.ipsos.com.br/imagens/release /6Tend\%C3\%AAnciasVarejo\%20abr08.pdf. Acessado em 17/06/2011.

Site operadora Vivo. Disponível em http://www.vivo.com.br. Acessado em 05/08/2012. Site Teleco. Inteligência em Telecomunicações. Disponível em http://www.teleco.com.br. Acessado em 05/08/2012.

Data do recebimento do artigo: 28/09/2012

Data do aceite de publicação: 14/01/2013

Revista Brasileira de Marketing - REMark, São Paulo, v. 12, n. 1, p. 223-250, jan./mar. 2013. 